\title{
Elements of healthy death: a thematic analysis
}

\author{
Fatemeh Estebsari ${ }^{1 *}$, Mohammad Hossein Taghdisi ${ }^{2}$, Davood Mostafaei ${ }^{3}$, Zahra Rahimi $^{4}$
}

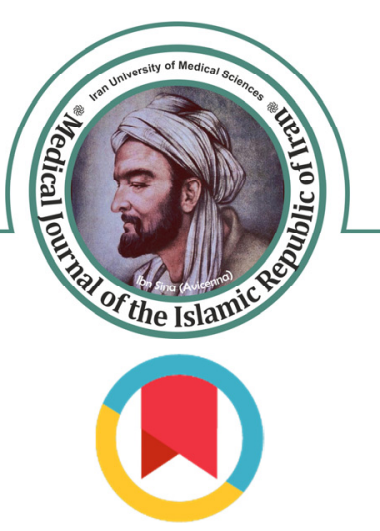

\section{Abstract}

Background: Death is a natural and frightening phenomenon, which is inevitable. Previous studies on death, which presented a negative and tedious image of this process, are now being revised and directed towards acceptable death and good death. One of the proposed terms about death and dying is "healthy death", which encourages dealing with death positively and leading a lively and happy life until the last moment. This study aimed to explain the views of Iranians about the elements of healthy death.

Methods: This qualitative study was conducted for 12 months in two general hospitals in Tehran (capital of Iran), using the thematic analysis method. After conducting 23 in-depth interviews with 21 participants, transcription of content, and data immersion and analysis, themes, as the smallest meaningful units were extracted, encoded and classified.

Results: One main category of healthy death with 10 subthemes, including dying at the right time, dying without hassle, dying without cost, dying without dependency and control, peaceful death, not having difficulty at dying, not dying alone and dying at home, inspired death, preplanned death, and presence of a clergyman or a priest, were extracted as the elements of healthy death from the perspective of the participants in this study.

Conclusion: The study findings well explained the elements of healthy death. Paying attention to the conditions and factors causing healthy death by professionals and providing and facilitating quality services for patients in the end stage of life make it possible for patients to experience a healthy death.

Keywords: End of life, Good death, Healthy Death, Element, Thematic analysis

Copyright $\odot$ Iran University of Medical Sciences

Cite this article as: Estebsari F, Taghdisi MH, Mostafaei D, Rahimi Z. Elements of healthy death: a thematic analysis. Med J Islam Repub Iran. 2017 (23 Mar); 31:24. https://doi.org/10.18869/mjiri.31.24

\section{Introduction}

Life goes on continuously from birth to death. Death still exists as one of the life events and an old tradition of creation system and as an inevitable end stage of life. Regardless of cultural background, people deal with death based on a variety of beliefs, attitudes, superstitions, fears, and hopes. People's needs should be taken into account in a comprehensive definition of death. When a person is about to die, their relatives and friends think how they can provide the conditions for a good death. End of life is a stage of life in which one's death is imminent (1). People who are about to die are individuals or patients in the end stage of their life because of aging, physical conditions, and disease (2). Currently, most studies on death are being revised to achieve acceptable death (3). Various terms and labels have been proposed for this concept. While the

Corresponding author: Dr Fatemeh Estebsari, fa_estebsari@yahoo.com

1. Department of Community Health Nursing, School of Nursing and Midwifery, Shahid Beheshti University of Medical Sciences, Tehran, Iran.

2. Department of Health Education\& Promotion, School of Public Health, Iran University of Medical Sciences, Tehran, Iran.

3. Shahid Beheshti University of Medical Sciences, Tehran, Iran.

4. Department of Health Education, School of Public Health, Iran University of Medical Sciences, Tehran, Iran. majority of texts use the term "good death" $(4,5)$, others have applied terms such as appropriate death (6), healthy death $(7,8)$, correct death $(9)$, happy death $(10)$, peaceful death (11), dying well (12), natural death (13), beautiful death (14), and good ending $(9,15)$.

According to the emphases of the WHO in Ottawa Charter (16) about giving importance to all needs of people and particularly the needs of those who are about to die and also respecting the death, the concept of healthy death has clearly been reflected along with other healthrelated concepts (17). Health promotion at dying or healthy death means to empower patients to deal with death positively, leading to a lively and happy life until the last moment (18). The quality of end of life care is a major challenge for patients, their families, and health

$\uparrow$ What is "already known" in this topic:

According to the emphases of the WHO in Ottawa Charter about giving importance to die and the death, the concept of health promotion at dying or healthy death has clearly been reflected empowering patients to deal with death positively until the last moment.

\section{$\rightarrow$ What this article adds:}

The concept of healthy death is expanded this study based on the cultural and religious backgrounds in Iran, which are different from the Western views. 
Table 1. Characteristics of participants $(\mathrm{N}=23)$

\begin{tabular}{|c|c|c|c|c|c|c|c|}
\hline \multirow{2}{*}{ Characteristics of the Participants } & \multicolumn{2}{|c|}{$\operatorname{Sex} n(\%)$} & \multirow{2}{*}{$\begin{array}{c}\text { Age } \\
\text { Range } \\
\text { (Year) }\end{array}$} & \multicolumn{3}{|c|}{ Education n (\%) } & \multirow{2}{*}{$\begin{array}{c}\text { Work Experience } \\
\text { (Year) }\end{array}$} \\
\hline & Male & Female & & Primary & Secondary & Higher & \\
\hline Patients & $2(9)$ & $3(13)$ & $27-64$ & $2(9)$ & $2(9)$ & $3(13)$ & - \\
\hline Patients Companions & $2(9)$ & $2(9)$ & $16-48$ & - & $2(9)$ & $2(9)$ & - \\
\hline Nurse & $1(4)$ & $2(9)$ & $31-41$ & - & - & $3(13)$ & $3-10$ \\
\hline Physician & $3(13)$ & - & $44-57$ & - & - & $3(13)$ & $3-15$ \\
\hline Psychologist & $1(4)$ & $2(9)$ & $39-41$ & - & - & $3(13)$ & $1-18$ \\
\hline Clergymen & $3(13)$ & - & $47-51$ & - & - & $3(13)$ & 6-15 \\
\hline
\end{tabular}

professionals and policymakers (19). These care services should be equally provided for all people (20). This study aimed to explain the views and perceptions of Iranian participants about healthy death elements.

\section{Methods}

In this study, thematic analysis method was used to identify the elements of healthy death in end-of-life patients. These patients, due to their special conditions, are not able to express their needs and desires. Hence, their families, medical staff, psychologists, and clergymen were interviewed. Using in-depth interviews, we elicited the views, opinions, and beliefs of participants about good, happy, easy and comfortable death, preparation for death, and providing conditions for a good death. Sampling was done, using purposive homogenous method. As part of the study, end-of-life patients were firstly identified in hospitals and then their families were interviewed.

\section{Study Population}

The first participant was the caregiver of a patient with advanced cancer hospitalized in the oncology ward. In additions, doctors and nurses who provide services to these patients, psychologists, and clergymen as experts were interviewed. In total, 23 in-depth interviews were conducted with 21 participants during July 2014 to July 2015. Participant selection process was continued until data saturation. In this study, data saturation occurred in the $21^{\text {th }}$ interview. However, two other interviews were conducted to ensure reliability. Characteristics of participants is summarized in Table 1.

\section{Interview}

The study objectives were explained to the participants and then they were asked to fill out a consent form for expressing their satisfaction with conscious and voluntary participation in the research. The participants were assured that the information they provided would remain confidential and the results would be published generally. The participants could drop out of the study at any time. The interview content was recorded by the permission of the interviewee. The interview was conducted at a time and place determined by the participants, and each interview lasted for 45-60 minutes. The interviews were performed, using semi-structured and unstructured approaches (21). Before the interview, we prepared a list of topics necessary to cover the information, and tried to maintain the consistency between the questions and the interview objectives. The interview started with more general questions and continued with more specific ones. Some of the questions asked in interviews were as follows: What is a good death in your opinion? In what condition do you like to die? How the conditions for a good and comfortable death can be provided for the patients? When and in which circumstance do you like to deal with death? What is your opinion about a good, comfortable, happy and peaceful death?

The interview content was transcribed verbatim immediately after each interview. Data analysis was done with constant comparison and concurrent with data collection. Analysis of the interview content was done, using Krippendorff method of thematic analysis approach, which includes data collection, data reduction, deduction, and analysis (22). The content of each interview was read several times, and themes were extracted, encoded, and classified; theme was defined as a coherent integration of the disparate pieces of data that constitute the findings (23).

\section{Trustworthiness of Data}

The trustworthiness of qualitative analysis is often presented, using terms such as credibility, dependability, conformability, and transferability (24). These are the most common measures to achieve rigor in qualitative studies (23).

Credibility deals with the focus of the research and refers to confidence in how well data and processes of analysis address the intended focus. To ensure the credibility of data, the method of "control by researchers" was used. For this purpose, two co-workers as "peer check" and a specialist observer of qualitative research as "external check" were asked to assist us (25). In this regard, some parts of the research data were given to a researcher, who was not associated with this study, as an external observer, to find whether he/she has the same understanding of the data. Consistency in encoding between the observer and the researcher was more than $85 \%$. In addition, responsive validity method was used to compare what was perceived by the researches with the real intention of the participants. For this purpose, participants were provided with the initial extracted codes to conform or correct them (Member Check) (26).

Another aspect of trustworthiness is dependability. Dependability refers to the stability of data over time and under different conditions. Therefore, it is important to state the principles and criteria used to select participants and find the participants' main characteristics so that the transferability of the results to other contexts could be assessed. To ensure the creditability of data, we applied prolonged engagement method (27). To achieve an optimal understanding, communication with the participants lasted for 12 months. 


\begin{tabular}{ll}
\hline Themes /Main Categories & Subthemes \\
\hline Healthy Death & Dying at the right time \\
& Dying without hassle \\
& Dying without cost \\
& Dying without dependency and control \\
& Peaceful death \\
& Not having difficulty at dying \\
& Not dying alone and dying at home near the family members \\
& Inspired death \\
& Preplanned death \\
& Presence of a clergyman or priest \\
\hline
\end{tabular}

Conformability refers to the objectivity and implies that the data accurately represent the information that the participants provided, and interpretations of those data are not invented by the inquirer (24). Trustworthiness also includes the question of transferability, which refers to "the extent to which the findings can be transferred to other settings or groups' (24).

\section{Data Analysis}

All data analysis and data management were done using MAXQDA software.

\section{Results}

The participants aged 22-60 yrs., with a minimum of 47 yrs. Most of them had a high school diploma and had different careers. One main category/ theme of healthy death with 10 subthemes was extracted as the elements of healthy death as follows:

Subtheme 1- Dying at the Right Time: Participants believed that a good and appropriate death is one that occurs at the right time. They stated that death is good and appropriate at the ages of $80-85$ after a long life, full enjoyment of life, having no wish, and having no unfinished business.

A 27-year-old woman, whose mother was afflicted with cancer, said, "It is too early for my mother to die. She is still young, it is now the time for her to rest and have pleasure. Death is good at old ages when all the body organs are exhausted."

Subtheme 2- Dying without Hassle: Not upsetting the family members, relatives, and acquaintances and not disturbing the lives of others were items mentioned by the participants as the characteristics of a good and acceptable death.

A 37-year-old caregiver of a cancer patient, said, "I do not want my death to become a tragedy to my family. I do not want to bother or annoy anyone." A 32-year-old caregiver with a sister who has cancer stated, "My 28-year-old sister has cancer. She has an 8-year-old daughter. Her illness has reached a stage that she is constantly hospitalized. Her husband could not take leave, so her husband's family and ours are also involved. My sister always apologizes to us and is really sad about this situation."

Subtheme 3- Dying without Cost: The costs of medical and care services for the treatment of incurable diseases and special care for patients in the end stage of life have always put so much pressure on families.

A 28-year-old caregiver of a patient said, "I like to die with the minimum possible cost. I think that a good death is a low-cost one. I do not like for my family to pay a lot for me and have trouble for providing the expenses." A 42-year-old male afflicted with cancer stated, "I wish that the funeral costs were covered by insurance so that families and acquaintances were not forced to bear the pressure for holding a decent funeral."

Subtheme 4- Dying without Dependency: Having care, financial and emotional independence and having control over individual and family life, the environment, and events were important to the participants. In their opinion, not being a burden to the family, friends, and acquaintances and having control over life were mentioned as the indicators of an acceptable death. A 49-year-old oncologist stated, "Most patients want to die in the best status of heath, not to be a burden to their family and acquaintances, and have control over their individual and family life, the environment, and events." Being independent in personal activities was another concern raised by the participants. A 45-year-old caregiver said, "I want to be independent until the last moment and do everything without help. I do not like to be a burden to my spouse and children." A 34-year-old nurse from the oncology ward quoted from a patient, "I do not like to be so sick that I cannot do my own work. I do not like to be dependent on others for going to the toilet and putting on clothes. In my opinion, when you are dependent on others, you should do everything that they say and you have to bear many things. I cannot accept such circumstances. It is hard to even imagine it. Suppose that others make decisions about you instead of yourself. In such circumstances, I prefer to die sooner."

The participants also complained about restrictions caused by their illness and hospitalization. A 42-year-old caregiver said, "When you're very sick and hospitalized, then you should obey the nurses and doctors and be on a certain regime. You cannot do the things you like and you have no right. I really hate such circumstance."

Subtheme 5- Peaceful Death: Dying easy, being carefree when dying, dying happily and comfortably, and dying fearlessly and without anxiety were some of the items mentioned by the participants about peaceful death and dying comfortably. A 46-year-old clergyman stated, "The families of most patients who are about to die ask us to be with the patients and pray for their peace of soul and a comfortable passing,"

A 48-year-old wife of a husband with cancer said, "I want to die in peace and without worrying about anyone 
or anything. My husband is dying, but he is restless and worried about the future of our children."

Subtheme 6- Not Having Difficulty When Dying: Having no pain and passing easily are of the factors mentioned by the participants about a healthy death.

A 41-year-old caregiver of a cancer patient stated, "I have seen many patients in this ward who had severe pain before dying. When they died, all of their relatives and acquaintances said that now their patient is comfortable and free of pain. Even the daughter of a cancer patient told me that she wished her father could pass away sooner and bear less pain."

Subtheme 7- Not Dying Alone and Dying at Home Near the Family Members: The participants stated that a healthy death to them means to die at home, being near to their family until the last moment.

A 34-year-old nurse of the oncology ward said, "Against our and his doctor's wish, my brother asked to be discharged from the hospital and go home. He has willed us that not let him die in the hospital. He wants to die at home. We respect his desire." A 38-year-old brother of a patient stated, "Patients prefer to surrender to death at the familiar environment of their own home and besides their family members and acquaintances."

A 34-year-old caregiver of a patient stated, "I have a grandmother who always asks us not to bother her by taking her to the hospital when she is too bad and there is no hope for her treatment. She likes to die easily and comfortably ay home."

Subtheme 8-Inspired Death: Being informed about the death and not dying suddenly were some of the items mentioned by the participants about a healthy death. A 37year-old caregiver of a cancer patient said,"I would like to be notified of the time of my death, and try to prepare myself for death. I would like to die this way. My patient is about to die now and has no opportunity for doing anything, but I need opportunity before dying."

Subtheme 9- Preplanned Death: Testation and determining the status of the property, the way of holding the funeral, and burial place, saying goodbye to the family and friends, seeking forgiveness, visiting a clergyman or priest were some of the things that the participants stated that liked to do as a preparation for death. A 43-year-old psychologist said, "It is better that people think about death, either in health or illness, and prepare themselves for dealing with it." A 46-year-old sister of a cancer patient stated, "It is recommended that people determine the way they like their funeral to be held, costs, burial place, and even the text of funeral declaration. When people do these on their own, they have actually accepted the reality of death and will be less worried about it."

A 54-year-old psychologist said, "If people have a plan for their death, then it would become easier to them. For example, people can write their will, determine the place of burial and the way of holding the funeral, say goodbye to friends and acquaintances, and seek for forgiveness from others and God. These can help people to die more easily and more carefree."

Subtheme 10-Presence of a Clergyman or Priest: Death evokes preoccupations with life after death and the related beliefs. Finding answer to the questions about death, the afterlife, and the destiny of human after death were some items that the participants mentioned to be more prominent at the time of illness. One of the demands made by the participants for their patients was the presence of a clergyman or priest at their bedside to pray and ask for forgiveness. A 55-year-old clergyman said, "Patients have willed their families to bring a clergyman to pray for them and recite some parts of the Quean they are about to die."

Discussion

Several factors contribute to the experience of a healthy death. Table 2 demonstrates the 10 elements of a healthy death obtained in this study. Considering the elements of healthy death extracted from this study, all the participants liked to die in comfortable condition and without disturbing others' life. In some references, healthy death has been defined as paying attention to the needs and demands of patients at the time of dying and satisfying them. In addition, healthy death means taking into account the needs and demands of the patients, and their family and friends $(7,28)$. In some studies, it has been emphasized that psychological, social, economic, and spiritual needs of both patients and their families should be met to provide conditions for healthy and good death for those patients who are dying (9). The concept of healthy death in this study is similar to that of the good death in other studies, but more comprehensive. In this study, the concept of healthy death is based on the cultural and religious backgrounds in Iran, which are different from the Western views.

In addition, the concept of healthy death is different from the concept of easy death. In some references, good death has been defined as helping a patient to die sooner without having pain. This is similar to easy death, while according to Kellehear's view, good death is not equal to easy death (29). Nowadays, easy death has been recognized as something official and legal with special conditions in some countries. This is done in many cases without being criminally prosecuted, because respecting the wishes of people at the time of death is one of the indicators of healthy death (7). According to the beliefs of the Iranian people, sustainment of life is respected until the last moment. Although the participants of this study did not like their patients to bear pain, they believed that easy death (euthanasia) is against the ethics. They believed that only God has the authority over the lives of people, and humans should not violate this right (30). They only wanted the pain and suffering of their patient to be relieved through medical interventions. Their beliefs about this issue were in contrast to the Western views (1).

The simplest definition of good death is to take into account and meet the needs and demands of the patients who are about to die (14), while healthy death means a kind of death in which the needs and demands of the dying patients, and their family and friends are taken into account (8). In this study, the participants also believed that no stress or pressure should be imposed on the patients' families.

Many dying patients and their families see themselves in a disadvantaged position. The often feel that they have given the control of their life to health professionals, while 
the patients want to be respected because they are about to die (31). Preserving and respecting the dignity of the end of life patients, who want to have a sense of control over their death to be able to make decisions and run their death, is very essential. One of the proposed strategies for gaining control is to support patients and their families in a way that empower them to maintain control over their own life (32). These supports should involve accessibility to the supports of the professional staff, identification of individual coping skills, ensuring the participation of patients and their families in the caring process, considering the family as a unit, keeping the open communication, maintaining the importance and continuity of communication, and providing necessary information (33).

According to the participants of this study, we should be prepared enough to have a healthy death. In the Iranian and Islamic culture, there are certain customs and practices for a person who is about to die. Farewell to family and friends, writing the will, determining the way of holding the funeral and burial place, and addressing the status of movable and immovable property are some of the actions for being prepared for death. These actions are in the area of psychology. Planning for death is a suitable strategy both for patients and their families to deal with different reactions of death (34). In most peoples' view, death is good when they have lived enough and there is no unfinished business to do. Inspired death was identified as another element of healthy death in this study. However, being aware and informed of death has been introduced as an element of healthy death.

One of the components of a healthy death is to help patients and families to pass through the stage of mourning and accept that their patient is in the end of life stage. In this study, the role of psychologists, counselors, clergymen, and religious beliefs was revealed as helpful factors for passing through the stage of mourning. In Iran, given the cultural conditions, beliefs about death are rooted in religion. The Holly Quran has mentioned what we should do to have a comfortable and happy death (35). Consulting a religious expert could be very helpful for finding the answers to the questions about death and the afterlife (36). In this study, paying attention to one's beliefs and especially his/her demands and needs at the time of death has been emphasized. However, the participants mentioned talking to a clergyman as a helpful factor for passing through the stage of mourning. This is consistent with the findings of other studies, which have mentioned the presence of a priest for soothing the grief (37). In addition, religious beliefs, praying, seeking forgiveness, and presence of a clergyman were other mentioned items for providing a good quality of life for patients in the end of life. Seeking forgiveness, praying, and talking to clergymen before death were some of the wishes and desires of the participants in this study, and they insisted that their demands be respected.

The participants stated that not being left alone, being with the family, and dying at home near the family are elements of a healthy death. They described dying at home as a peaceful death. In their opinion, the support of family and friends and particularly not leaving the patient alone are the major source of spiritual and mental support for patients who are about to die. Patients in the end of life stage require emotional and mental support more than ever. Being in the familiar environment of home near the family creates a sense of confidence in patients, and somewhat reduces their fear, and makes it easier to endure their pains and sufferings. However, social isolation caused by the breaking of ties with friends and even family is sometimes inevitable for a person who is about to die. The family of an end-of-life patient prefers to be near their beloveds and not leave them alone. Factors such as spending time with the spouse, children, friends, and family and being alone for a while have been proven to be effective in improvement of the quality of life of patients who are about to die (38). In a study conducted by Higginson (39), paying attention to the needs and demands of a person who is about to die such as the need for ensuring the comfort, the need to express the emotions, and the need for comfort and support from family members were mentioned as an alleviating measure that could be done by the family of the dying patients. Presence of the end-oflife patient at home has advantages for both the patient and his/her family. The patient's fear and anxiety will greatly reduce if they are near their family, providing a peace of mind for the patient. The family also will be carefree because they can be near their patient until the last moment and do anything they can for him/her (40). However, the presence of an end-of-life patient at home requires providing proper facilities and special conditions for the patient. To provide good care for the dying patients at home, the psychological, social, economic, and spiritual needs of both the patients and their families should be taken into account and met (41). The presence of a dying patient at home is economically cost-effective for families and also provides the possibility for admission of other patients to the hospital (42). However, the impact of the stress and pressure caused by the presence of a dying patient at home on his/her caregivers in the family should not be ignored. Making the decision to do so is subject to the full assessment of all aspects. Paying attention to the needs and demands of the caregiver is one of the elements of a healthy death. However, training the caregivers, as a strategy and a need, is essential. These trainings should involve not only caring for the dying patient and preparing for healthy death conditions, but also the way of dealing with the factors threatening the health of the caregiver and crisis management. Paying attention to the needs and demands of dying patients and their families is of standards (Standard COP.7) accrediting a health care system. In this standard, sympathetic treatment of patients, respecting their religious values and beliefs and cultural priorities, engages the patients and their families in all aspects of care, responding to the mental, emotional, spiritual, and cultural concerns when the patients and their families have been taken into account (43). Not having pain when dying was one of the mentioned items. Respecting this demand of patients is respecting the right to have a healthy death. Pain management and psychological care should be included in providing care to the dying patients. The use of counseling and psychiatric services to help patients and 
their families would be effective in dealing with adversity and preparation for death. The use of counseling services, psychiatrists, and psychologists is not common in hospitals and will be provided at the request of the patient's doctor. However, these services should be provided for all dying patients and their families (44). Changing the society's attitude towards the dying patients is also of great importance. End-of-life patients, despite their special conditions, are still alive and have legal rights that should be respected. The fact that a patient is about to die does not allow us to dent them the opportunity to live and die at a high quality.

Another concern mentioned for dying patients was dependence and lack of control over their own life. According to the participants in this study, being independence was one of the important points for having a high quality life. In a study conducted by Gallagher (45), the participants stated that pain control, having control over the surrounding environment, ability to have meals, renal and bowel excretion control, ability to breathe easily, and having the required strength and energy to do everyday affairs are effective factors for experiencing a good death.

Dying without cost was another element of healthy death, which was obtained in this study. The costs of care and drug for the dying patients cannot be ignored. Economic support of the government in the provision of medicines and the support of private and non-private social groups and organizations can be helpful in this regard (46). Development of a specific insurance law for dying patients to cover the care services is another recommended strategy for reducing the pressure of costs on families of dying patients.

The findings of this study may help the health sector policymakers and planners to pay a special attention to the issue of quality of life for dying patients. This research was a qualitative study conducted on a few number of participants. Hence, the findings have a limited generalizability. The study findings can be used as a basis for future studies on designing, implementing, and evaluating health promotion intervention programs to provide conditions for healthy death.

\section{Conclusion}

Dying comfortably is the right of all humans. Like a healthy person, all health aspects of a dying patient should be considered. In addition, the needs and demands of their family should be taken into account. Therefore, it is recommended that the dying persons to be treated and valued like other people.

\section{Acknowledgements}

This paper was extracted from a research project entitled: "The Capability of Social Structure for Coping with Death: Healthy Death (First Phase)", which was approved by Tehran University of Medical Sciences under the code of 12638. The authors would like to thank all participants in this study who thoroughly helped us.

Conflict of Interests: The authors declare that there is no conflict of interest regarding the publication of this manu- script.

\section{References}

1. Miyashita M, Morita T, Sato K, Tsuneto S, Shima Y. A Nationwide Survey of Quality of End-of-Life Cancer Care in Designated Cancer Centers, Inpatient Palliative Care Units, and Home Hospices in Japan: The J-HOPE Study. J Pain Sympt Manag. 2015;50(1):38-47.e3.

2. Pizzi MA. Promoting health, wellness, and quality of life at the end of life: hospice interdisciplinary perspectives on creating a good death. J All Health. 2014;43(4):212-20.

3. Kallel H, Dammak H, Bahloul M, Ben Hamida C, Chelly H, Rekik N, et al. A good death: another break in the wall. Intens Care Med. 2006;32(11):1915-6.PMID: 17019551[PubMed - indexed for MEDLINE]

4. Ko E, Kwak J, Nelson-Becker H. What Constitutes a Good and Bad Death?: Perspectives of Homeless Older Adults. Death Stud. 2015;39(7):422-32.

5. Jin X, Liu GG, Luo N, Li H, Guan H, Xie F. Is bad living better than good death? Impact of demographic and cultural factors on health state preference. Quality of Life Res. Jin X, Liu GG, Luo N, Li H, Guan H, Xie F. Is bad living better than good death? Impact of demographic and cultural factors on health state preference. Qualit Life Res. 2016 Apr 1;25(4):979.

6. Ko E, Cho S, Perez RL, Yeo Y, Palomino H. Good and bad death: exploring the perspectives of older Mexican Americans. J Gerontolog Soc Work. 2013;56(1):6-25.

7. Hattori K, Ishida DN. Ethnographic study of a good death among elderly Japanese Americans. Nurs Health Sci. 2012;14(4):488-94.

8. Russell P, Sander R. Palliative care: promoting the concept of a healthy death. Br J Nurs. 1998;7(5):256-61.

9. Schulte-Wissermann H. [The good death]. Kinderkrankenschwester: Organ der Sektion Kinderkrankenpflege / Deutsche Gesellschaft fur Sozialpadiatrie und Deutsche Gesellschaft fur Kinderheilkunde. 2014;33(3):88

10. Slama O. [Palliative medicine and the "good death"]. Vnitrni lekarstvi. 2014;60 (Suppl 2):75-9.

11. Brunjes GB. Practical approaches to spiritual pain. Asian Pacific journal of cancer prevention: APJCP. 2010;11 Suppl 1:37-9.

12. Gerstorf D, Ram N, Goebel J, Schupp J, Lindenberger U, Wagner GG. Where people live and die makes a difference: Individual and geographic disparities in well-being progression at the end of life. Psychol Aging. 2010;25(3):661-76.

13. van 't Land K. Long life, natural death. The learned ideal of dying in late medieval commentaries on Avicenna's Canon. Early Sci Med. 2014;19(6):558-83.

14. Oliver T, O'Connor SJ. Perceptions of a "good death" in acute hospitals. Nursing times. 2015;111(21):24-7.

15. Gregory A, Armstrong R. In search of a good ending. Med J Australia. 2013;198(4):175.

16. WHO. WHO Global Health Promotion Conferences. Health promotion. WHO Global Health Promotion Conferences:http://www.who.in t/healthpromotion/conferences/previous/ottawa/en/.

17. Trankle SA. Is a good death possible in Australian critical and acute settings?: physician experiences with end-of-life care. BMC palliative care. 2014;13:41.

18. Kinoshita H, Maeda I, Morita T, Miyashita M, Yamagishi A, Shirahige Y, et al. Place of death and the differences in patient quality of death and dying and caregiver burden. Journal of clinical oncology : official journal of the American Society of Clinical Oncology. 2015;33(4):357-63.

19. Estebsari F, Taghdisi MH, Mostafaei D, Jamshidi E, Latifi M. Determining the Factors Contributing to Quality of Life of Patients at the Last Stage of Life: A Qualitative Study. Iran Red Crescent Med J. 2013;15(12):1-6. e13594.

20. Beckstrand RL, Rohwer J, Luthy KE, Macintosh JL, Rasmussen RJ. Rural Emergency Nurses' End-of-Life Care Obstacle Experiences: Stories from the Last Frontier. Journal of emergency nursing: JEN. 2015:

21. Johnstone MJ, Hutchinson AM, Redley B, Rawson H. Nursing Roles and Strategies in End-of-Life Decision Making Concerning Elderly Immigrants Admitted to Acute Care Hospitals: An Australian Study. Journal of transcultural. 2016 Sep;27(5):471-9.

22. Pellico LH, Gilliam WP, Lee AW, Kerns RD. Hearing new voices: registered nurses and health technicians experience caring for chronic 
pain patients in primary care clinics. Open Nurs J. 2014;8:25-33.

23. Vaismoradi M, Turunen H, Bondas T. Content analysis and thematic analysis: Implications for conducting a qualitative descriptive study. Nurs Health Sci. 2013;15,:398-405.

24. Elo S, Kääriäinen M, Kanste O, Pölkk T, Utriainen K, Kyngäs H. Qualitative Content Analysis: A Focus on Trustworthiness. SAGE Open. 2014:1-10

25. Hold JL, Blake BJ, Ward EN. Perceptions and experiences of nursing students enrolled in a palliative and end-of-life nursing elective: A qualitative study. Nurs Edu Today. 2015;35(6):777-81.

26. Paradis E, Leslie M, Gropper MA. Interprofessional rhetoric and operational realities: an ethnographic study of rounds in four intensive care units. Adv Health Sci Educ Theory Pract. 2016 Oct;21(4):735-48.

27. Memaryan N, Rassouli M, Nahardani SZ, Amiri P. Integration of spirituality in medical education in iran: a qualitative exploration of requirements. J Evid Based Complementary Altern Med. 2015 Nov $24 ; 2015$.

28. Omery A. A healthy death. Heart \& Lung. 1991;20(3):310-1.

29. Kellehear A. On dying and human suffering. Palliat Med. 2009;23(5):388-97.

30. Tayeb MA, Al-Zamel E, Fareed MM, Abouellail HA. A "good death": perspectives of Muslim patients and health care providers. Annals Saudi Med. 2010;30(3):215-21.

31. van Gurp J, Soyannwo O, Odebunmi K, Dania S, van Selm M, van Leeuwen E, et al. Telemedicine's Potential to Support Good Dying in Nigeria: A Qualitative Study. PloS one. 2015;10(6):e0126820.

32. Raisio H, Vartiainen P, Jekunen A. Defining a Good Death: A deliberative democratic view. J Palliat Care. 2015;31(3):158-65.

33. Cagle JG, Pek J, Clifford M, Guralnik J, Zimmerman S. Correlates of a good death and the impact of hospice involvement: findings from the national survey of households affected by cancer. Support Care Cancer. 2015;23(3):809-18.

34. Cottrell L, Duggleby W. The "good death": An integrative literature review. Palliat Support Care. 2016:1-27.

35. Iranmanesh S, Hosseini H, Esmaili M. Evaluating the "good death" concept from Iranian bereaved family members' perspective. J Support Oncol. 2011;9(2):59-63.

36. LeBaron VT, Cooke A, Resmini J, Garinther A, Chow V, Quinones R, et al. Clergy Views on a Good Versus a Poor Death: Ministry to the Terminally Ill. J Palliat Med. 2015;18(12):1000-7.

37. Omidvari S. Spiritual health; concepts and challenges. Specialty Quran Interdisciplinary Res. 2008;1:6-17.

38. Seal K, Murray CD, Seddon L. Family stories of end-of-life cancer care when unable to fulfill a loved one's wish to die at home. Palliat Support Care. 2015;13(3):473-83.

39. Higginson IJ, Costantini M. Dying with cancer, living well with advanced cancer. Eur J Cancer. 2008;44(10):1414-24.

40. Krishna LK, Alsuwaigh R, Miti PT, Wei SS, Ling KH, Manoharan D. The influence of the family in conceptions of personhood in the palliative care setting in Singapore and its influence upon decision making. Am J Hospice Palliat Care. 2014;31(6):645-54.

41. Adamson E, Cruickshank S. A 'good death' at home: community nurses helping to make it possible. $\mathrm{Br} \mathrm{J}$ Commun Nurs. 2013;18(1):40-2.

42. Gomes B, Higginson IJ. Factors influencing death at home in terminally ill patients with cancer: systematic review. BMJ (Clinical research ed). 2006;332(7540):515-21.

43. Higginson IJ, Evans CJ. What is the evidence that palliative care teams improve outcomes for cancer patients and their families? Cancer J. 2010;16(5):423-35.

44. Lorenz KA, Lynn J, Dy SM, Shugarman LR, Wilkinson A, Mularski RA, et al. Evidence for improving palliative care at the end of life: a systematic review. Annal Intern Med. 2008;148(2):147-59.

45. Gallagher A. The good death. Nursing ethics. 2013;20(3):243-4.

46. Gomes B, McCrone P, Hall S, Koffman J, Higginson IJ. Variations in the quality and costs of end-of-life care, preferences and palliative outcomes for cancer patients by place of death: the QUALYCARE study. BMC cancer. 2010;10(1):1. 